\section{Psychological Medicine}

cambridge.org/psm

\section{Editorial}

Cite this article: Kelleher I, Cannon M (2021). A neural efficiency-threshold model to understand psychotic experiences. Psychological Medicine 51, 1777-1782. https:// doi.org/10.1017/S0033291721001495

Received: 20 August 2020 Revised: 11 February 2021 Accepted: 6 April 2021

First published online: 3 June 2021

Key words:

Delusions; hallucinations; psychosis; psychotic experiences

Author for correspondence:

Ian Kelleher, E-mail: iankelleher@rcsi.ie

\title{
A neural efficiency-threshold model to understand psychotic experiences
}

Ian Kelleher ${ }^{1,2,3}$ (D) and Mary Cannon ${ }^{3,4}$

${ }^{1}$ School of Medicine, University College Dublin, Dublin, Ireland; ${ }^{2}$ Lucena Clinic, Rathgar, Dublin, Ireland;
${ }^{3}$ Department of Psychiatry, Royal College of Surgeons in Ireland, Dublin, Ireland and ${ }^{4}$ Beaumont Hospital, Dublin,
Ireland Introduction

Psychotic experiences have been a rich area of psychiatric research for the past two decades (Johns \& Van Os, 2001). These are perceptual abnormalities and unusual thought content, which, in most cases, are associated with at least a degree of intact reality testing. Much of the psychotic experiences research to date has focused on prevalence, risk factors and persistence. We believe, for the field to move forward, it is important to develop a broader understanding of psychotic experiences. This editorial proposes a framework for understanding psychotic experiences from a psychosocial and neurobiological perspective, which we term the neural efficiency threshold model.

\section{Research to date}

Early research on psychotic experiences focused on a continuum with, and prediction of, psychotic disorders (Johns \& Van Os, 2001; Poulton et al., 2000; Van Os, Linscott, Myin-Germeys, Delespaul, \& Krabbendam, 2009). As with a depression continuum from mild sadness to pervasively depressed mood, it was proposed that psychotic experiences could be conceptualised as existing on a continuum from minor perceptual abnormalities and overvalued unusual thought content to the fully psychotic hallucinations and delusions of schizophrenia. Meta-analyses suggested 5-7\% of the general adult population experienced at least occasional psychotic experiences (Linscott \& Van Os, 2013; Van Os et al., 2009) and follow-up studies showed that these individuals were at elevated risk of developing psychotic disorders (Poulton et al., 2000; Welham et al., 2009).

Research that followed highlighted that, as opposed to a homotypic relationship with psychotic disorder, psychotic experiences are predictive of a wide range of mental disorders (Fisher et al., 2013; McGrath et al., 2016; Werbeloff et al., 2012; Wigman et al., 2012). Indeed, although only a small minority of individuals with psychotic experiences go on to develop a psychotic disorder, a high proportion develop other, more common mental disorders, including depressive, anxiety, behavioural and substance use disorders (Healy \& Cannon, 2020; Kelleher et al., 2012a; b; c; Rimvall et al., 2020; Scott, Chant, Andrews, \& McGrath, 2006; Trotta et al., 2020; Varghese et al., 2011; Wigman et al., 2012).

A wide variety of factors have been shown to be associated with psychotic experiences, including lower IQ (Cannon et al., 2002; Johns et al., 2004), adversity (Croft et al., 2019; Crush, Arseneault, \& Fisher, 2018; McGrath et al., 2017; Morgan et al., 2014; Newbury et al., 2018; Oh, Cogburn, Anglin, Lukens, \& DeVylder, 2016), poorer coping skills (Lin et al., 2011; Wigman et al., 2014a), migration (Laurens, West, Murray, \& Hodgins, 2008; Scott et al., 2006), ethnicity (El Bouhaddani, van Domburgh, Schaefer, Doreleijers, \& Veling, 2019; Oh, Yang, Anglin, \& DeVylder, 2014) and socioeconomic factors (Scott et al., 2006), as well as genetic and molecular variation (Niculescu et al., 2015; Pain et al., 2018; Ramsay et al., 2013).

Our own research has highlighted psychotic experiences as indicators of psychopathology severity, demonstrating that, compared to individuals with mental disorders without psychotic experiences, individuals with psychotic experiences have a higher psychiatric symptom burden (Kelleher, Clarke, Rawdon, Murphy, \& Cannon, 2013a), greater multimorbidity (Kelleher, Cederlof, \& Lichtenstein, 2014a; Kelleher et al., 2012b), more suicidal behaviour (Kelleher et al., 2014a; Kelleher et al., 2013b; Kelleher et al., 2012b), cognitive deficits (Blanchard et al., 2010; Kelleher et al., 2013a) and poorer socio-occupational functioning (Healy et al., 2018; Kelleher et al., 2015; Wigman et al., 2014a). Researchers have also demonstrated that psychotic experiences are associated with high levels of psychological distress (Armando et al., 2010), more mental health service use (Bhavsar et al., 2017) and poorer treatment responses to both pharmacotherapy (Perlis et al., 2011) and psychotherapy (Wigman et al., 2014b). 


\section{A broader biopsychosocial framework}

We believe it is now timely to consider psychotic experiences in a broader framework of neurobiological and psychosocial functioning, with illness severity representing just one aspect. Specifically, we believe that psychotic experiences can be conceptualised as markers of a clinically significant mental threshold - the threshold being where mental distress transitions to dysfunction in neural systems integration and communication, which we term the neural efficiency threshold model. One of the earliest clinical signs of crossing this threshold, we believe, is the emergence of problems with sensory perception skills and, as a result, hallucinatory experiences.

Supporting evidence of neural systems dysfunction in individuals with psychotic experiences comes from a number of neurocognitive and neuromotor studies. From the perspective of neurocognition, a wide range of deficits have been demonstrated in individuals with formal psychotic disorders (Barch \& Ceaser, 2012; Bowie \& Harvey, 2005; Green et al., 2011; Szöke et al., 2008). Lesser degrees of cognitive impairment have also been observed in more common mental disorders - notably depression (Rock, Roiser, Riedel, \& Blackwell, 2014; Service et al., 2020; Weiser et al., 2004) - which might suggest that neural systems dysfunction extends more broadly to general psychopathology. However, research on cognitive function in common mental disorders has typically failed to assess or account for co-occurring psychotic experiences. Our model suggests that common mental disorders that do not have co-occurring psychotic experiences would not be associated with significant cognitive impairment but that we would see progressive cognitive effects as psychotic experiences emerge and become more severe.

Preliminary support for this comes from Barnett et al., who looked at childhood cognitive function as it longitudinally related to psychopathology and psychotic experiences (Barnett et al., 2012). Although initial analyses suggested there may be a relationship between psychopathology and poorer cognitive performance, this relationship was, in fact, entirely accounted for by co-occurring psychotic experiences. That is, individuals with psychopathology who did not have psychotic experiences did not demonstrate poorer cognitive performance.

Similarly, in our own research, we have found that young people with psychotic experiences performed more poorly than their peers on multiple measures of cognitive processing speed, as well as in non-verbal working memory (Kelleher et al., 2013a), findings that were not accounted for by general psychopathology. Individuals with psychotic experiences have, furthermore, also been shown to score more poorly on tests of intellectual ability (Cannon et al., 2002; Johns et al., 2004).

Other evidence of neural systems dysfunction associated with psychotic experiences comes from neuromotor studies. In the Dunedin study, poorer motor skills development in infancy and early childhood was predictive of psychotic experiences at age 11 years (Cannon et al., 2002). We have also found evidence of neuromotor skills deficits in older children with psychotic experiences in terms of poorer scores on the Purdue pegboard task (Blanchard et al., 2010). What is more, we found that poorer childhood pegboard motor performance was predictive of psychotic experiences into adulthood (Carey et al., 2019).

Because of the high degree of regional specialisation within the brain, complex mental processes are dependent not just upon the efficiency of relevant brain regions but also upon high-speed communication between the different hubs that must cooperate to faithfully execute these processes. This high-speed cooperation is dependent upon the integrity and efficiency of tracts connecting diffuse neural networks, referred to as the connectome. The connectome is the matrix of neurons connecting and facilitating communication between different (specialised) brain regions.

The development of an efficient connectome allowed the evolution of a high degree of regional specialisation in the human brain because it facilitated rapid communication and coordination between the many specialised neural hubs involved in executing complex mental processes. The connectome might be likened to a complex road network, with the major white matter tracts representing the motorways, and a whole series of progressively smaller 'road networks' that connect diffuse brain regions. Each 'road network' has a limited capacity beyond which 'traffic' can no longer efficiently travel, resulting in poorer interaction and coordination between hubs.

Complex mental processes depend on rapid, coordinated transmission of information between multiple hubs. If delays arise in parts of this information transmission process then the complex mental processes carried out by these hubs will be disturbed. For example, information transmission problems in neural circuits involved in sensory perception will mean that smooth integration of sensory perceptual experiences will breakdown, leading to hallucinatory experiences. The greater the latency in information transmission, the more severe the hallucinations. This applies to many complex mental processes that require coordination between neural hubs, such as sensoryperception, motor, cognitive, social and language skills - all processes that are implicated in psychosis. Psychosis, then, might be considered the evolutionary price for developing highly specialised brains - asynchrony or poor integration of neural activity from one hub to the other may give rise to psychotic experiences.

\section{Why are some individuals more sensitive to information transmission latencies than others? Developmental issues and individual differences}

The synaptic pruning process that defines adolescent brain development leads to more efficient integration and coordination between brain hubs ('neurons that fire together, wire together'). We suggest that this is the reason why the prevalence of psychotic experiences markedly decreases over the course of adolescence (Kelleher et al., 2012a): where this maturational process proceeds smoothly, neural efficiency increases, meaning that the threshold for disordered integration and coordination (which precipitates psychotic experiences) is less likely to occur.

Individuals for whom the synaptic pruning process is less successful, however, will have lower thresholds at which their key information transmission systems break down, meaning that psychotic experiences are more likely - the more disordered the synaptic pruning process, the lower the neural efficiency threshold.

As well as between person differences, there may also be within person differences in terms of vulnerability to deficits in one domain over another. For example, an individual may have relatively poor connectivity in certain brain regions, such as in brain hubs involved in auditory sensory processing, but relatively better connectivity in other regions, such as in brain hubs involved in language or in limb movements, meaning that deficits will be more marked in terms of auditory hallucinations, with fewer problems with disorganised speech or behaviour. Individual variation in risk for psychotic experiences may be dependent upon an 
interaction between the integrity of the connectome and the levels of demand or mental stress placed upon the individual (and, therein, their available neural resources), with each individual having their own personal threshold, beyond which communication cannot continue efficiently, leading to the emergence of psychotic experiences. That is, the more efficient the connectome, the greater the demand needed to overwhelm neural resources and cause psychotic experiences.

Connectome efficiency (or the speed of transfer of information facilitated by the connectome), we believe, may also be the reason why psychotic experiences are far more prevalent in childhood than in adolescence and adulthood. Adolescence represents the key developmental stage during which consolidation of the hubs of the connectome occurs (Whitaker et al., 2016). A more efficient connectome, resulting from a healthy consolidation process, will, we suggest, result in reduced vulnerability to psychotic experiences.

We suggest that the relative hypoconnectivity of the preadolescent brain may be the reason that psychotic experiences are for more prevalent in children. We hypothesise that, given their stage of brain development, even relatively low levels of demand may overwhelm neural resources in otherwise healthily developing younger children and precipitate psychotic experiences.

In keeping with the above, emerging neuroimaging research in individuals with psychotic experiences has shown reduced integrity of white matter tracts that are important in coordinating high-speed information processing between distributed neural networks (Amico et al., 2017; Drakesmith et al., 2015; Drakesmith et al., 2016; Jacobson et al., 2010; Jacobson McEwen et al., 2014; O'Hanlon et al., 2015; Orr, Turner, \& Mittal, 2014). Most recently, neuroimaging research has demonstrated reduced functional connectivity in young people with psychotic experiences, including relative hypoconnectivity affecting the default mode network, central executive network, salience network and motor network (O'Neill et al., 2020). Importantly, recent research suggests that hypoconnectivity associated with psychotic experiences may be dynamic and state-dependent (Mennigen et al., 2020).

Once an individual passes their neural efficiency threshold, effects on a wide range of mental processes may begin to emerge: impaired communication between hubs involved in logical thought, for example, may give rise to delusional beliefs and thought disorder. Impaired communication between hubs involved in social cognition may give rise to social skills deficits. Impaired communication between hubs involved in language may give rise to disorganised speech. Impaired communication between hubs involved in complex motor skills may give rise to disorganised behaviour. Crucially, problems integrating neural activity from hubs involved in sensory perception may give rise to hallucinations.

Although early motor, language, social or thought process problems may be subtle enough to be overlooked, unusual perceptual experiences such as perceiving one's thoughts as though they are aloud represents a qualitative difference that is difficult to ignore. Therefore, hallucinations may emerge as one of the earliest signs of neural systems dysfunction and could represent a clinical bellwether of an individual passing their neural efficiency threshold. Although problems in neurocognition, social cognition, language and motor skills might emerge at the same time, these deficits may need to be significantly more advanced before they become readily apparent.

\section{Psychotic experiences and trauma}

Beyond neurocognitive and neuromotor effects, we suggest that dysfunction associated with passing a neural efficiency threshold is also a major factor contributing to the strong relationship between psychotic experiences and trauma (Arseneault et al., 2011; Kelleher et al., 2013c; McGrath et al., 2017; Morrison, Frame, \& Larkin, 2003; Schäfer \& Fisher, 2011). Psychological stress, arising from exposure to adverse life events, will drive increased interaction between relevant neural hubs, including those involved in threat and stress responses. This increased neural activity ('traffic') in the connectome reduces capacity for interaction and high-speed coordination between other hubs. The greater the degree of distress, the greater the network capacity demand that is taken up responding to this stressor, which results in reduced network capacity for other interacting hubs. Therefore, coordination between neural hubs that are dependent on highspeed interaction may be delayed, including coordination between hubs involved in sensory perception, which may give rise to hallucinatory experiences.

\section{Psychotic experiences and suicidal behaviour}

We suggest that reduced efficiency of cooperation between hubs involved in complex mental processes may serve to increase the risk of suicidal behaviour at the same time as increasing risk of psychotic experiences (Bromet et al., 2017; DeVylder, Lukens, Link, \& Lieberman, 2015; Fisher et al., 2013; Hielscher et al., 2019; Kelleher et al., 2014a, b; Yates et al., 2019). This includes, for example, cooperating hubs involved in the execution of complex problem-solving skills (Barzilay et al., 2019), hubs involved in language skills that allow one to verbalise one's challenges, and hubs involved in complex social skills that allow one to effectively elicit help from others. Taken together, these problems will result in difficulties generating sophisticated solutions in the face of complex problems and, as a result, may contribute to the risk of suicide.

\section{Testable hypotheses}

We propose that the neural efficiency-threshold model allows the generation and testing of many different hypotheses with regard to psychotic experiences. For example, from a cognitive perspective, the model suggests that neurocognitive deficits are a feature of the emergence of psychotic experiences rather than of the underlying mental disorder per se. From a developmental perspective, the model suggests that stressful situations are more likely to elicit psychotic experiences in pre-adolescent children than in adolescents and adults. From a functional perspective, the model suggests that, within individuals with mental disorders, the presence of psychotic experiences would be better predictors of functioning than information on the severity of symptoms of the underlying disorder itself.

One particular important testable hypothesis, which arises from this model, is that individuals exposed to adverse life events who develop psychotic experiences should have a higher risk of suicidal behaviour than individuals who experience the same adverse life events but who do not develop psychotic experiences. In that way, psychotic experiences might act as a measurable marker of the subjective impact of adverse life events, including in terms of suicidal behaviour risk. 
We hope this neural efficiency threshold model will provide a useful framework for a broader bio-psycho-social understanding of psychotic experiences to guide and inspire future research.

Author contributions. IK drafted the original manuscript. MC made important intellectual contributions to revisions.

Conflict of interest. Dr Kelleher and Dr Cannon have nothing to disclose.

Role of funding source. Funding bodies played no role in the production of this manuscript.

\section{References}

Amico, F., O’Hanlon, E., Kraft, D., Oertel-Knochel, V., Clarke, M., Kelleher, I., ... Cannon, M. (2017). Functional connectivity anomalies in adolescents with psychotic symptoms. PLoS One, 12(1), e0169364. doi: 10.1371/ journal.pone.0169364.

Armando, M., Nelson, B., Yung, A. R., Ross, M., Birchwood, M., Girardi, P., \& Nastro, P. F. (2010). Psychotic-like experiences and correlation with distress and depressive symptoms in a community sample of adolescents and young adults. Schizophrenia Research, 119(1-3), 258-265.

Arseneault, L., Cannon, M., Fisher, H. L., Polanczyk, G., Moffitt, T. E., \& Caspi, A. (2011). Childhood trauma and children's emerging psychotic symptoms: A genetically sensitive longitudinal cohort study. American Journal of Psychiatry, 168(1), 65-72.

Barch, D. M., \& Ceaser, A. (2012). Cognition in schizophrenia: Core psychological and neural mechanisms. Trends in Cognitive Sciences, 16(1), 27-34.

Barnett, J. H., McDougall, F., Xu, M. K., Croudace, T. J., Richards, M., \& Jones, P. B. (2012). Childhood cognitive function and adult psychopathology: Associations with psychotic and non-psychotic symptoms in the general population. The British Journal of Psychiatry, 201(2), 124-130.

Barzilay, R., Calkins, M. E., Moore, T. M., Wolf, D. H., Satterthwaite, T. D., Scott, J. C., ... Gur, R. E. (2019). Association between traumatic stress load, psychopathology, and cognition in the Philadelphia neurodevelopmental cohort. Psychological Medicine, 49(2), 325-334.

Bhavsar, V., Maccabe, J. H., Hatch, S. L., Hotopf, M., Boydell, J., \& McGuire, P. (2017). Subclinical psychotic experiences and subsequent contact with mental health services. BJPsych Open, 3(2), 64-70.

Blanchard, M. M., Jacobson, S., Clarke, M. C., Connor, D., Kelleher, I., Garavan, H., ... Cannon, M. (2010). Language, motor and speed of processing deficits in adolescents with subclinical psychotic symptoms. Schizophrenia Research, 123(1), 71-76. doi: 10.1016/j.schres.2010.05.028.

Bowie, C. R., \& Harvey, P. D. (2005). Cognition in schizophrenia: Impairments, determinants, and functional importance. Psychiatric Clinics, 28(3), 613-633.

Bromet, E. J., Nock, M. K., Saha, S., Lim, C. C., Aguilar-Gaxiola, S., Al-Hamzawi, A., ... Degenhardt, L. (2017). Association between psychotic experiences and subsequent suicidal thoughts and behaviors: A crossnational analysis from the world health organization world mental health surveys. JAMA Psychiatry, 74(11), 1136-1144.

Cannon, M., Caspi, A., Moffitt, T. E., Harrington, H., Taylor, A., Murray, R. M., \& Poulton, R. (2002). Evidence for early-childhood, pan-developmental impairment specific to schizophreniform disorder: Results from a longitudinal birth cohort. Archives of General Psychiatry, 59(5), 449-456.

Carey, E., Dooley, N., Gillan, D., Healy, C., Coughlan, H., Clarke, M., ... Cannon, M. (2019). Fine motor skill and processing speed deficits in young people with psychotic experiences: A longitudinal study. Schizophrenia Research, 204, 127-132.

Croft, J., Heron, J., Teufel, C., Cannon, M., Wolke, D., Thompson, A., ... Zammit, S. (2019). Association of trauma type, age of exposure, and frequency in childhood and adolescence with psychotic experiences in early adulthood. JAMA Psychiatry, 76(1), 79-86.

Crush, E., Arseneault, L., \& Fisher, H. L. (2018). Girls get by with a little help from their friends: Gender differences in protective effects of social support for psychotic phenomena amongst poly-victimised adolescents. Social Psychiatry and Psychiatric Epidemiology, 53(12), 1413-1417.
DeVylder, J. E., Lukens, E. P., Link, B. G., \& Lieberman, J. A. (2015). Suicidal ideation and suicide attempts among adults with psychotic experiences: Data from the collaborative psychiatric epidemiology surveys. JAMA Psychiatry, 72(3), 219-225. doi: 10.1001/jamapsychiatry.2014.2663.

Drakesmith, M., Caeyenberghs, K., Dutt, A., Zammit, S., Evans, C. J., Reichenberg, A., ... Jones, D. K. (2015). Schizophrenia-like topological changes in the structural connectome of individuals with subclinical psychotic experiences. Human Brain Mapping, 36(7), 2629-2643.

Drakesmith, M., Dutt, A., Fonville, L., Zammit, S., Reichenberg, A., Evans, C. J., ... David, A. S. (2016). Mediation of developmental risk factors for psychosis by white matter microstructure in young adults with psychotic experiences. JAMA Psychiatry, 73(4), 396-406.

El Bouhaddani, S., van Domburgh, L., Schaefer, B., Doreleijers, T. A., \& Veling, W. (2019). Psychotic experiences among ethnic majority and minority adolescents and the role of discrimination and ethnic identity. Social Psychiatry and Psychiatric Epidemiology, 54(3), 343-353.

Fisher, H., Caspi, A., Poulton, R., Meier, M., Houts, R., Harrington, H., ... Moffitt, T. (2013). Specificity of childhood psychotic symptoms for predicting schizophrenia by 38 years of age: A birth cohort study. Psychological Medicine, 43(10), 2077.

Green, M. F., Bearden, C. E., Cannon, T. D., Fiske, A. P., Hellemann, G. S., Horan, W. P., ... Sergi, M. J. (2011). Social cognition in schizophrenia, part 1: Performance across phase of illness. Schizophrenia Bulletin, 38(4), 854-864.

Healy, C., Campbell, D., Coughlan, H., Clarke, M., Kelleher, I., \& Cannon, M. (2018). Childhood psychotic experiences are associated with poorer global functioning throughout adolescence and into early adulthood. Acta Psychiatrica Scandinavica, 138(1), 26-34.

Healy, C., \& Cannon, M. (2020). We need to talk about prevention. American Journal of Psychiatry, 177(4), 285-287.

Hielscher, E., Connell, M., Lawrence, D., Zubrick, S. R., Hafekost, J., \& Scott, J. G. (2019). Association between psychotic experiences and non-accidental self-injury: Results from a nationally representative survey of adolescents. Social Psychiatry and Psychiatric Epidemiology, 54(3), 321-330.

Jacobson, S., Kelleher, I., Harley, M., Murtagh, A., Clarke, M., Blanchard, M., ... Cannon, M. (2010). Structural and functional brain correlates of subclinical psychotic symptoms in 11-13 year old schoolchildren. Neuroimage, 49 (2), 1875-1885.

Jacobson McEwen, S., Connolly, C., Kelly, A., Kelleher, I., O’hanlon, E., Clarke, M., ... Sheehan, E. (2014). Resting-state connectivity deficits associated with impaired inhibitory control in non-treatment-seeking adolescents with psychotic symptoms. Acta Psychiatrica Scandinavica, 129(2), 134-142.

Johns, L. C., Cannon, M., Singleton, N., Murray, R. M., Farrell, M., Brugha, T., ... Meltzer, H. (2004). Prevalence and correlates of self-reported psychotic symptoms in the British population. The British Journal of Psychiatry, 185 (4), 298-305.

Johns, L. C., \& Van Os, J. (2001). The continuity of psychotic experiences in the general population. Clinical Psychology Review, 21(8), 1125-1141.

Kelleher, I., Cederlof, M., \& Lichtenstein, P. (2014a). Psychotic experiences as a predictor of the natural course of suicidal ideation: A Swedish cohort study. World Psychiatry, 13(2), 184-188. doi: 10.1002/wps.20131.

Kelleher, I., Clarke, M. C., Rawdon, C., Murphy, J., \& Cannon, M. (2013a). Neurocognition in the extended psychosis phenotype: Performance of a community sample of adolescents with psychotic symptoms on the MATRICS neurocognitive battery. Schizophrenia Bulletin, 39(5), 10181026. doi: $10.1093 / \mathrm{schbul} / \mathrm{sbs} 086$.

Kelleher, I., Connor, D., Clarke, M. C., Devlin, N., Harley, M., \& Cannon, M. (2012a). Prevalence of psychotic symptoms in childhood and adolescence: A systematic review and meta-analysis of population-based studies. Psychological Medicine, 42(9), 1857-1863. doi: 10.1017/S0033291711002960.

Kelleher, I., Corcoran, P., Keeley, H., Wigman, J. T., Devlin, N., Ramsay, H., ... Cannon, M. (2013b). Psychotic symptoms and population risk for suicide attempt: A prospective cohort study. JAMA Psychiatry, 70(9), 940-948. doi: 10.1001/jamapsychiatry.2013.140.

Kelleher, I., Devlin, N., Wigman, J. T., Kehoe, A., Murtagh, A., Fitzpatrick, C., \& Cannon, M. (2014b). Psychotic experiences in a mental health clinic sample: Implications for suicidality, multimorbidity and functioning. Psychological Medicine, 44(8), 1615-1624. doi: 10.1017/S0033291713002122. 
Kelleher, I., Keeley, H., Corcoran, P., Lynch, F., Fitzpatrick, C., Devlin, N., ... Cannon, M. (2012b). Clinicopathological significance of psychotic experiences in non-psychotic young people: Evidence from four population-based studies. British Journal of Psychiatry, 201(1), 26-32. doi: 10.1192/ bjp.bp.111.101543.

Kelleher, I., Keeley, H., Corcoran, P., Ramsay, H., Wasserman, C., Carli, V., ... Cannon, M. (2013c). Childhood trauma and psychosis in a prospective cohort study: Cause, effect, and directionality. American Journal of Psychiatry, 170(7), 734-741.

Kelleher, I., Lynch, F., Harley, M., Molloy, C., Roddy, S., Fitzpatrick, C., \& Cannon, M. (2012c). Psychotic symptoms in adolescence index risk for suicidal behavior: Findings from 2 population-based case-control clinical interview studies. Archives of General Psychiatry, 69(12), 1277-1283.

Kelleher, I., Wigman, J. T., Harley, M., O’Hanlon, E., Coughlan, H., Rawdon, C., ... Cannon, M. (2015). Psychotic experiences in the population: Association with functioning and mental distress. Schizophrenia Research, 165(1), 9-14. doi: 10.1016/j.schres.2015.03.020.

Laurens, K., West, S., Murray, R., \& Hodgins, S. (2008). Psychotic-like experiences and other antecedents of schizophrenia in children aged 9-12 years: A comparison of ethnic and migrant groups in the United Kingdom. Psychological Medicine, 38(8), 1103-1111.

Lin, A., Wigman, J., Nelson, B., Vollebergh, W. A., Van Os, J., Baksheev, G., ... Yung, A. (2011). The relationship between coping and subclinical psychotic experiences in adolescents from the general population-a longitudinal study. Psychological Medicine, 41(12), 2535-2546.

Linscott, R., \& Van Os, J. (2013). An updated and conservative systematic review and meta-analysis of epidemiological evidence on psychotic experiences in children and adults: On the pathway from proneness to persistence to dimensional expression across mental disorders. Psychological Medicine, 43(6), 1133-1149.

McGrath, J. J., Saha, S., Al-Hamzawi, A., Andrade, L., Benjet, C., Bromet, E. J., ... Demyttenaere, K. (2016). The bidirectional associations between psychotic experiences and DSM-IV mental disorders. American Journal of Psychiatry, 173(10), 997-1006.

McGrath, J. J., Saha, S., Lim, C. C., Aguilar-Gaxiola, S., Alonso, J., Andrade, L. H., ... Cardoso, G. (2017). Trauma and psychotic experiences: Transnational data from the world mental health survey. The British Journal of Psychiatry, 211(6), 373-380.

Mennigen, E., Jolles, D. D., Hegarty, C. E., Gupta, M., Jalbrzikowski, M., Olde Loohuis, L. M., ... Bearden, C. E. (2020). State-dependent functional dysconnectivity in youth with psychosis spectrum symptoms. Schizophrenia Bulletin, 46(2), 408-421.

Morgan, C., Reininghaus, U., Reichenberg, A., Frissa, S., Hotopf, M., Hatch, S. L., \& Team, S. S. (2014). Adversity, cannabis use and psychotic experiences: Evidence of cumulative and synergistic effects. The British Journal of Psychiatry, 204(5), 346-353.

Morrison, A. P., Frame, L., \& Larkin, W. (2003). Relationships between trauma and psychosis: A review and integration. British Journal of Clinical Psychology, 42(4), 331-353.

Newbury, J., Arseneault, L., Caspi, A., Moffitt, T. E., Odgers, C. L., \& Fisher, H. L. (2018). Cumulative effects of neighborhood social adversity and personal crime victimization on adolescent psychotic experiences. Schizophrenia Bulletin, 44(2), 348-358.

Niculescu, A. B., Levey, D., Phalen, P., Le-Niculescu, H., Dainton, H., Jain, N., ... Weber, H. (2015). Understanding and predicting suicidality using a combined genomic and clinical risk assessment approach. Molecular Psychiatry, 20(11), 1266-1285.

Oh, H., Cogburn, C. D., Anglin, D., Lukens, E., \& DeVylder, J. (2016). Major discriminatory events and risk for psychotic experiences among black Americans. American Journal of Orthopsychiatry, 86(3), 277.

Oh, H., Yang, L. H., Anglin, D. M., \& DeVylder, J. E. (2014). Perceived discrimination and psychotic experiences across multiple ethnic groups in the United States. Schizophrenia Research, 157(1-3), 259-265.

O’Hanlon, E., Leemans, A., Kelleher, I., Clarke, M. C., Roddy, S., Coughlan, H., ... Cannon, M. (2015). White matter differences among adolescents reporting psychotic experiences: A population-based diffusion magnetic resonance imaging study. JAMA Psychiatry, 72(7), 668-677. doi: 10.1001/ jamapsychiatry.2015.0137.
O’Neill, A., Carey, E., Dooley, N., Healy, C., Coughlan, H., Kelly, C., ... Cannon, M. (2020). Multiple network dysconnectivity in adolescents with psychotic experiences: A longitudinal population-based study. Schizophrenia Bulletin, 177(4), 285-287.

Orr, J. M., Turner, J. A., \& Mittal, V. A. (2014). Widespread brain dysconnectivity associated with psychotic-like experiences in the general population. NeuroImage: Clinical, 4, 343-351.

Pain, O., Dudbridge, F., Cardno, A. G., Freeman, D., Lu, Y., Lundstrom, S., ... Ronald, A. (2018). Genome-wide analysis of adolescent psychotic-like experiences shows genetic overlap with psychiatric disorders. American Journal of Medical Genetics Part B: Neuropsychiatric Genetics, 177(4), 416-425..

Perlis, R. H., Uher, R., Ostacher, M., Goldberg, J. F., Trivedi, M. H., Rush, A. J., \& Fava, M. (2011). Association between bipolar spectrum features and treatment outcomes in outpatients with major depressive disorder. Archives of General Psychiatry, 68(4), 351-360. doi: 10.1001/archgenpsychiatry.2010.179.

Poulton, R., Caspi, A., Moffitt, T. E., Cannon, M., Murray, R., \& Harrington, H. (2000). Children's self-reported psychotic symptoms and adult schizophreniform disorder: A 15-year longitudinal study. Archives of General Psychiatry, 57(11), 1053-1058.

Ramsay, H., Kelleher, I., Flannery, P., Clarke, M. C., Lynch, F., Harley, M., ... Cannon, M. (2013). Relationship between the COMT-Val158Met and BDNF-Val66Met polymorphisms, childhood trauma and psychotic experiences in an adolescent general population sample. PLoS One, 8(11), e79741. doi: 10.1371/journal.pone.0079741.

Rimvall, M. K., van Os, J., Verhulst, F., Wolf, R. T., Larsen, J. T., Clemmensen, L., ... Jeppesen, P. (2020). Mental health service use and psychopharmacological treatment following psychotic experiences in preadolescence. American Journal of Psychiatry, 177(4), 318-326.

Rock, P., Roiser, J., Riedel, W., \& Blackwell, A. (2014). Cognitive impairment in depression: A systematic review and meta-analysis. Psychological Medicine, 44(10), 2029-2040.

Schäfer, I., \& Fisher, H. L. (2011). Childhood trauma and psychosis-what is the evidence? Dialogues in Clinical Neuroscience, 13(3), 360.

Scott, J., Chant, D., Andrews, G., \& McGrath, J. (2006). Psychotic-like experiences in the general community: The correlates of CIDI psychosis screen items in an Australian sample. Psychological Medicine, 36(2), 231-238.

Service, S. K., Upegui, C. V., Ramírez, M. C., Port, A. M., Moore, T. M., Umanes, M. M., ... López, M. C. (2020). Distinct and shared contributions of diagnosis and symptom domains to cognitive performance in severe mental illness in the Paisa population: A case-control study. The Lancet Psychiatry, 7(5), 411-419.

Szöke, A., Trandafir, A., Dupont, M.-E., Meary, A., Schürhoff, F., \& Leboyer, M. (2008). Longitudinal studies of cognition in schizophrenia: Meta-analysis. The British Journal of Psychiatry, 192(4), 248-257.

Trotta, A., Arseneault, L., Caspi, A., Moffitt, T. E., Danese, A., Pariante, C., \& Fisher, H. L. (2020). Mental health and functional outcomes in young adulthood of children with psychotic symptoms: A longitudinal cohort study. Schizophrenia Bulletin, 46(2), 261-271.

Van Os, J., Linscott, R. J., Myin-Germeys, I., Delespaul, P., \& Krabbendam, L. (2009). A systematic review and meta-analysis of the psychosis continuum: Evidence for a psychosis proneness-persistence-impairment model of psychotic disorder. Psychological Medicine, 39(2), 179-195.

Varghese, D., Scott, J., Welham, J., Bor, W., Najman, J., O'Callaghan, M., ... McGrath, J. (2011). Psychotic-like experiences in major depression and anxiety disorders: A population-based survey in young adults. Schizophrenia Bulletin, 37(2), 389-393.

Weiser, M., Reichenberg, A., Rabinowitz, J., Knobler, H., Lubin, G., Yazvitzky, R., ... Davidson, M. (2004). Cognitive performance of male adolescents is lower than controls across psychiatric disorders: A population-based study. Acta Psychiatrica Scandinavica, 110(6), 471-475.

Welham, J., Scott, J., Williams, G., Najman, J., Bor, W., O'callaghan, M., \& McGrath, J. (2009). Emotional and behavioural antecedents of young adults who screen positive for non-affective psychosis: A 21-year birth cohort study. Psychological Medicine, 39(4), 625.

Werbeloff, N., Drukker, M., Dohrenwend, B. P., Levav, I., Yoffe, R., van Os, J., ... Weiser, M. (2012). Self-reported attenuated psychotic symptoms as 
forerunners of severe mental disorders later in life. Archives of General Psychiatry, 69(5), 467-475.

Whitaker, K. J., Vértes, P. E., Romero-Garcia, R., Váša, F., Moutoussis, M., Prabhu, G., ... Rittman, T. (2016). Adolescence is associated with genomically patterned consolidation of the hubs of the human brain connectome. Proceedings of the National Academy of Sciences, 113(32), 9105-9110.

Wigman, J. T., Devlin, N., Kelleher, I., Murtagh, A., Harley, M., Kehoe, A., ... Cannon, M. (2014a). Psychotic symptoms, functioning and coping in adolescents with mental illness. BMC Psychiatry, 14, 97. doi: 10.1186/ 1471-244X-14-97.

Wigman, J. T., van Nierop, M., Vollebergh, W. A., Lieb, R., Beesdo-Baum, K., Wittchen, H. U., \& van Os, J. (2012). Evidence that psychotic symptoms are prevalent in disorders of anxiety and depression, impacting on illness onset, risk, and severity--implications for diagnosis and ultra-high risk research. Schizophrenia Bulletin, 38(2), 247-257. doi: 10.1093/schbul/sbr196.

Wigman, J. T., van Os, J., Abidi, L., Huibers, M. J., Roelofs, J., Arntz, A., ... Peeters, F. P. (2014b). Subclinical psychotic experiences and bipolar spectrum features in depression: Association with outcome of psychotherapy. Psychological Medicine, 44(2), 325-336. doi: 10.1017/S0033291713000871.

Yates, K., Lang, U., Cederlof, M., Boland, F., Taylor, P., Cannon, M., ... Kelleher, I. (2019). Association of psychotic experiences With subsequent risk of suicidal ideation, suicide attempts, and suicide deaths: A systematic review and meta-analysis of longitudinal population studies. JAMA Psychiatry, 76(2), 180-189. doi:10.1001/jamapsychiatry.2018.3514. 